\title{
QTc Prolongation in the Critically Ill: Tread with Caution!
}

\author{
Ashok Elangovan
}

Indian Journal of Critical Care Medicine (2020): 10.5005/jp-journals-10071-23403

The QT interval represents the period of ventricular depolarization and repolarization on the surface electrocardiograph (ECG). It is measured from the beginning of the QRS complex to the end of the T wave. When corrected for heart rate, it is called the corrected QT interval (QTc). Several methods are described to measure the QTc, none distinctly superior to another. ${ }^{1}$ Torsades de pointes is a polymorphic ventricular tachycardia seen in the context of prolonged QTC. While often self-reverting, it can progress to ventricular fibrillation and sudden cardiac death. Since its original description in 1966 by Dessertenne, ${ }^{2}$ significant advances have been made in the understanding of the electrophysiology of torsades de pointes. ${ }^{3}$ Cardiac morbidity and mortality associated with prolonged QTc have risen to prominence in recent times in the context of therapy with chloroquine/hydroxychloroquine and azithromycin for coronavirus disease (COVID-19).

Critically ill patients are susceptible to a wide range of arrhythmias due to multiple factors including hypoxia, hypovolemia, acidosis, dyselectrolytemias, sepsis, elevated endogenous sympathetic tone, exogenously administered catecholamines, organ insufficiencies such as renal or hepatic dysfunction, brain injuries/multitrauma, endocrine abnormalities, cardiac ischemia, and exposure to multiple drugs and their interactions. ${ }^{4}$ Critically ill patients have a high incidence of QTc prolongation (24-37\%) in different studies; new-onset prolongation maybe up to 200-fold higher compared to the general population. ${ }^{5-10}$ While the stress of critical illness can unmask a latent susceptibility to the long QT syndrome, the most common causes are drug related and the presence of significant dyselectrolytemias. A QTc interval of more than $500 \mathrm{~ms}$ should raise significant concern and necessitate action. Several classes of drugs have been associated with QTc prolongation to a variable extent. ${ }^{11}$ A large number of drugs prolong QTc by interfering with the human Ether-a-go-go-Related Gene ( $h E R G$ ) and the rapidly activating delayed rectifier potassium channels $(\mathrm{IKr})$, leading to delays in ventricular repolarization. ${ }^{3}$

Prolonged hospitalization and mortality have been documented in intensive care unit (ICU) patients with QTc prolongation, though it is unclear whether this is causal or merely an epiphenomenon. ${ }^{5-7,9,10}$ The QTc prolongation may merely be a marker of illness, both in acute illness and as a long-term marker of cardiovascular morbidity and mortality. ${ }^{5,6}$ The need for QTc monitoring in the ICU cannot be overemphasized. Pickham et al. observed that $69 \%$ of patients in critical care units had one or more indications for QTc monitoring, as recommended by the American Heart Association. ${ }^{12}$ An awareness of the incidence and causes of QTc prolongation and appropriate intervention in case of prolongation could potentially decrease the incidence of life-threatening arrhythmias. These interventions may include cessation of offending drugs, correction of electrolytes, and magnesium replacement.

In this issue of the journal, Farzanegan et al. conducted a prospective observational study in multiple ICUs of a single center over 6 months to identify the incidence and predictors
Department of Intensive Care Medicine, Queen Elizabeth Hospital, Adelaide, Australia

Corresponding Author: Ashok Elangovan, Department of Intensive Care Medicine, Queen Elizabeth Hospital, Adelaide, Australia, Phone: +919483506517, e-mail: docashoke@gmail.com

How to cite this article: Elangovan A. QTC Prolongation in the Critically III: Tread with Caution! Indian J Crit Care Med 2020;24(4):220-221.

Source of support: Nil

Conflict of interest: None

of QTc prolongation among critically ill patients between days 1 and 5 of admission. ${ }^{13}$ They observed a baseline incidence of QTc prolongation of $6.5 \%$, which increased to $15.7 \%$ on day 5 of admission. They identified multiple factors associated with baseline QTc prolongation on univariate analysis; however, on multiple logistic regression analysis, only alcohol addiction and admission due to injury/poisoning were significantly associated with prolonged QTc. Azithromycin administration was found to be a significant association on day 3. On day 5, an elevated creatinine (>1.3 $\mathrm{mg} \%)$ and admission to an emergency ICU were found to be of significance. The authors do not specify criteria for admission to the emergency ICU; it is also unclear whether there was a significantly higher number of toxicology admissions. Among patients with QTC prolongation, two patients succumbed to malignant ventricular arrhythmias; however, it is unclear whether there was preceding torsades de pointes. The authors also found a higher mortality among patients with QTc prolongation compared to those without; however, this was not statistically significant.

This is a single-center study with QTC values derived from ECGs performed on three different days of ICU admission. Continuous electronic monitoring could potentially capture more episodes of QTc prolongation. Considering the study design and the limited number of patients enrolled, a causal relationship between the factors identified and QTc prolongation cannot be definitively established. Nevertheless, the study reemphasizes the importance of the oft neglected QTc interval and the need for serial monitoring. The incidence of QTc prolongation in the present study seems substantially lower than other studies among a similar population. ${ }^{6,7,10}$ This could potentially be due to the variable methods used to calculate the QTc interval in these studies and the different cutoffs applied to define QTc prolongation. Furthermore, ECGs were not available in a third of the patients on day 5. The finding of increased mortality is consistent with the prior studies. ${ }^{7,9,10}$ In the FROG-ICU study, QTC prolongation was found to be independently associated with 30-day and 1-year mortality on adjusted analysis. ${ }^{9}$ This contrasts with the findings of a recent study by Russell et al. who found increased mortality in the prolonged QTc group; however, this was not related to arrhythmias as the

(c) The Author(s). 2020 Open Access This article is distributed under the terms of the Creative Commons Attribution 4.0 International License (https://creativecommons. org/licenses/by-nc/4.0/), which permits unrestricted use, distribution, and non-commercial reproduction in any medium, provided you give appropriate credit to the original author(s) and the source, provide a link to the Creative Commons license, and indicate if changes were made. The Creative Commons Public Domain Dedication waiver (http://creativecommons.org/publicdomain/zero/1.0/) applies to the data made available in this article, unless otherwise stated. 
direct cause of death. ${ }^{6}$ They concluded that QTc prolongation in the critically ill is common and associated with increased mortality; however, they suggested that QTC prolongation may merely represent an independent marker of the severity of illness.

Physician awareness of QTC prolongation among their patients may be limited; besides, remedial action may often not be undertaken. ${ }^{14}$ While the risks vs. benefits of persisting with a QTc prolonging drug need to be individualized to each patient, the importance of monitoring must be reinforced. Pharmacistled monitoring or continuous electronic monitoring with clinical decision support systems built into the electronic medical records may potentially be a way forward, combined with physician education. ${ }^{15,16}$ The QT interval has been proposed as an emerging vital sign for future practice. ${ }^{17}$ While this may be a bit far-fetched, it is imperative for us in the critical care community to be aware of the causes and consequences of QTc prolongation and to tread with caution.

\section{References}

1. Rautaharju PM, Surawicz B, Gettes LS, Bailey JJ, Childers R, Deal BJ, et al. AHA/ACCF/HRS recommendations for the standardization and interpretation of the electrocardiogram: part IV: the ST segment, T and $U$ waves, and the QT interval: a scientific statement from the american heart association electrocardiography and arrhythmias committee, council on clinical cardiology; the american college of cardiology foundation; and the heart rhythm society. Endorsed by the international society for computerized electrocardiology. J Am Coll Cardiol 2009;53(11):982-991. DOI: 10.1016/j.jacc.2008.12.014.

2. Dessertenne F. Ventricular tachycardia with 2 variable opposing foci. Arch Mal Coeur Vaiss 1966;59(2):263-272.

3. El-Sherif N, Turitto G, Boutjdir M. Acquired long QT syndrome and electrophysiology of torsade de pointes. Arrhythm Electrophysiol Rev 2019;8(2):122-130. DOI: 10.15420/aer.2019.8.3.

4. Boriani G, Fauchier L, Aguinaga L, Beattie JM, Blomstrom Lundqvist C, Cohen A, et al. European heart rhythm association (EHRA) consensus document on management of arrhythmias and cardiac electronic devices in the critically ill and post-surgery patient, endorsed by heart rhythm society (HRS), Asia pacific heart rhythm society (APHRS), cardiac arrhythmia society of southern Africa (CASSA), and latin american heart rhythm society (LAHRS). Europace 2019;21(1):7-8. DOI: 10.1093/europace/euy110.

5. Ding Y, Jeon R, Ran L, Pan W, Wang F, Li Q. New-onset QT prolongation is a novel predictor of mortality in critically ill patients. Crit Care 2019;23(1):229. DOI: 10.1186/s13054-019-2514-6.
6. Russell H, Churilov L, Toh L, Eastwood GM, Bellomo R. The incidence, predictors and outcomes of QTc prolongation in critically ill patients. J Crit Care 2019;54:244-249. DOI: 10.1016/j.jcrc.2019.09.014.

7. George TK, Chase D, Peter JV, Satyendra S, Kavitha R, George LR, et al. Association between a prolonged corrected QT interval and outcomes in patients in a medical intensive care unit. Indian J Crit Care Med 2015;19(6):326-332. DOI: 10.4103/0972-5229.158271.

8. Fernandes FM, Silva EP, Martins RR, Oliveira AG. QTc interval prolongation in critically ill patients: prevalence, risk factors and associated medications. PLoS ONE 2018;13(6):e0199028. DOI: 10.1371/ journal.pone.0199028.

9. Javanainen T, Ishihara S, Gayat E, Charbit B, Jurkko R, Cinotti R, et al. Prolonged corrected QT interval is associated with short-term and long-term mortality in critically ill patients: results from the FROG-ICU study. Intensive Care Med 2019;45(5):746-748. DOI: 10.1007/s00134019-05555-8.

10. Pickham D, Helfenbein E, Shinn JA, Chan G, Funk M, Weinacker $A$, et al. High prevalence of corrected QT interval prolongation in acutely ill patients is associated with mortality: results of the QT in practice (QTIP) study. Crit Care Med 2012;40(2):394-399. DOI: 10.1097/ CCM.0b013e318232db4a.

11. Woosley RL, Heise CW, Romero KA, www.Crediblemeds.org. QTdrugs List, Accessed 20th April 2020. AZCERT, Inc. 1822 Innovation Park Dr, Oro Valley, AZ 85755.

12. Pickham D, Helfenbein E, Shinn JA, Chan G, Funk M, Drew BJ. How many patients need QT interval monitoring in critical care units? Preliminary report of the QT in practice study. J Electrocardiol 2010;43(6):572-610. DOI: 1016/j.jelectrocard.2010.05.016.

13. Farzanegan B, Hosseinpoor Z, Baniasadi S, Seyyedi SR, Rajabi M. An Observational Study of QTC Prolongation in Critically III Patients: Identification of Incidence and Predictors. Indian J Crit Care Med 2020;24(4):270-275.

14. Good MM, Riad FS, Good CB, Shalaby AA. Provider response to QTc prolongation on standard 12-lead EKG: do we notice or do we care. Pacing Clin Electrophysiol 2016;39(11):1174-1180. DOI: 10.1111/ pace.12951.

15. Ng TM, Bell AM, Hong C, Hara JM, Touchette DR, Danskey KN, et al. Pharmacist monitoring of QTC interval-prolonging medications in critically ill medical patients: a pilot study. Ann Pharmacother 2008;42(4):475-482. DOI: 10.1345/aph.1K458.

16. Sharma S, Martijn Bos J, Tarrell RF, Simon GJ, Morlan BW, Ackerman MJ, et al. Providers' response to clinical decision support for QT prolonging drugs. J Med Syst 2017;41(10):161. DOI: 10.1007/s10916017-0803-7.

17. Giudicessi JR, Noseworthy PA, Ackerman MJ.TheQT interval.Circulation 2019;139(24):2711-2713. DOI: 10.1161/Circulationaha.119.039598. 